\title{
EMERGÊNCIA DE AMBIENTE PROPÍCIO À APRENDIZAGEM DA RELAÇÃO ENTRE PROJETO PEDAGÓGICO E AMBIENTE VIRTUAL EM CURSOS A DISTÂNCIA: UMA ABORDAGEM COMPLEXA
}

\author{
(EMERGENCE OF FAVORABLE ENVIRONMENT FOR \\ LEARNING AND THE RELATIONSHIP BETWEEN \\ EDUCATIONAL PROJECT IN VIRTUAL ENVIRONMENT \\ AND DISTANCE COURSES: AN COMPLEX APPROACH)
}

\author{
Eliamar Godoi \\ Universidade Federal de Uberlândia (UFU), Brasil \\ Roberval Montes da Silva \\ Universidade Estadual de Goiás (UEG), Brasil
}

\section{RESUMO}

Esse trabalho analisa um curso de graduação em Língua Inglesa ofertado à distância. A análise foi orientada pela teoria da complexidade cujo enfoque foi mais nas relações entre seus elementos e interagentes e menos nos resultados. Considerando o Projeto Pedagógico do curso analisado como um documento contextualizado, um dos desafios apontados nesse estudo consiste em buscar o melhor entendimento de fatores que possam facilitar a construção de um ambiente que seja propício à aprendizagem dos cursitas em EAD. Para esse estudo, adotamos algumas noções da teoria do caos/complexidade que serviram de base epistemológica para as análises e discussões desta pesquisa. Buscamos evidências de propriedades dos sistemas complexos tais como emergência, atratores, auto-organização, adaptabilidade e sensibilidade à condições iniciais e a fatores externos que incidiram nesse curso considerado um sistema complexo. Para tal, a análise incidiu na relação entre projeto pedagógico do curso e o seu Design instrucional bem como nas interações, nos fatores e elementos que puderam influenciar positiva ou negativamente a emergência de um ambiente favorável à aprendizagem. Da relação entre projeto pedagógico e ambiente virtual emergiram padrões de dimensões sociais tais como reciprocidade, colaboração ou a falta dela, ambientação e tentativas de aprendizagem. Entendemos que a melhor compreensão das características, funcionamento e padrões emergentes em cursos de graduação a distância possa contribuir para as discussões voltadas às práticas colaborativas com enfoque na aprendizagem em ambiente virtual.

Palavras-chave: ambiente de aprendizagem, educação a distância, complexidade. 


\begin{abstract}
This paper analyzes an online graduate course for teachers of English. The study is geared towards the theory of complexity. It focuses more on the relationships between various elements and the inter-agents in this process, and less on the results. In as far as the pedagogical design of this contextualized course, one of the challenges that were identified in the studies involved seeking a better understanding of the factors that facilitated the creation of an environment that was conducive to the learning of the course components. For this study, we adopted as a guiding principle some notions from chaos theory/complexity, which form the epistemological basis of the analyses and the discussions of this research. In addition, we researched the properties of complex systems such as emergence, attraction principles, self-organization, adaptability and sensitivity to initial conditions, as well as external factors that occurred during a complex system. To this end, the analysis focused on the relationship between the pedagogical aspects of the course (the project), and its instructional design, as well as online interactions and other factors and elements that could positively or negatively influence the creation of a favorable learning environment. The relationship between the educational project and the virtual environment led to other social dimensions such as reciprocity, collaboration (or lack thereof), learning strategies and learning environment. We conclude that the increased understanding of the characteristics, the functioning and the implementation of standards in distance education courses for teachers aids discussions about collaborative virtual environment practices in this field.
\end{abstract}

Keywords: learning environment, distance education, complexity.

O curso de graduação denominado Curso de Letras: licenciatura em Inglês e Literaturas de Língua Inglesa ofertado na modalidade a distância por uma Universidade Federal local confere ao egresso do curso a titulação de Licenciado em Letras com Habilitação em Inglês e Literaturas de Língua Inglesa. Tendo iniciado o processo no $1^{0}$ semestre do ano de 2011, esse Curso foi planejado para ser ofertado em 4 (quatro) anos completando uma carga horária de 2865 horas distribuídas em regime semestral. Com entrada única, ofereceu 200 (duzentas) vagas divididas em 50 (cinquenta) vagas para cada polo, a saber: Uberlândia, Araxá, Uberaba e Patos de Minas.

Nesse artigo, descrevemos esse curso de graduação Letras/Inglês à luz da teoria do caos/complexidade (Morin, 2003; Paiva, 2009), apresentando o seu Projeto Pedagógico-PP como documento contextualizado que compõe as condições iniciais para sua emergência no Ambiente Virtual de Aprendizagem-AVA. Dessa forma, por meio das interações ocorridas nos diversos fóruns do curso, analisamos o PP em sua relação com o Design instrucional na perspectiva da teoria do caos/complexidade. Para isso, incorporamos a essa descrição alguns fatores contextuais que restringiram ou favoreceram o processo de adaptação do curso enquanto sistema adaptativo complexo ao propiciar aprendizagem e formação no ambiente virtual do curso de Letras/Inglês como formação inicial para professores. 
Nessa direção, buscamos evidências de propriedades dos sistemas complexos tais como emergência, atratores, auto-organização, adaptabilidade e sensibilidade à condições iniciais e a fatores externos que incidiram no curso, assim como, incidem em todo e qualquer sistema complexo. O objetivo foi buscar na relação entre projeto pedagógico do curso de graduação em Letras/Inglês e o seu Design instrucional quais fatores e elementos puderam influenciar positiva ou negativamente a emergência de um ambiente favorável à aprendizagem e à formação de professores à distância. Essa ação implicou em reconhecer que as relações de ensino e aprendizagem planejadas para o curso não foram totalmente previsíveis nem totalmente aleatórias. Assim, questionamos: quais foram os padrões emergentes e adaptativos, os fatores e os elementos que puderam influenciar positiva ou negativamente a emergência de propriedades complexas no Design instrucional do Curso de Letras Inglês a Distância propiciando aprendizagem em contexto de Educação a Distância?

Para contextualizar o Projeto Pedagógico do CLIEAD (doravante PP), trazemos uma análise qualitativa desse documento em que tomamos como dado o texto do próprio PP no que se refere, principalmente, a apontamentos contextuais em que buscamos realçar aspectos que revelaram os processos interativos, além de aspectos que apontaram as ações pedagógicas articulando intenções, políticas e objetivos do curso. Sendo assim, apresentamos esse documento como parte inicial de um processo que culminou na organização e aplicação do CLIEAD em um AVA.

No sentido de entender essa nova perspectiva investigativa, exibimos uma definição do conceito de Complexidade. Morin (2003) define Complexidade como um tecido (complexus: o que é tecido em conjunto) de constituintes heterogêneos inseparavelmente associados que coloca o paradoxo do uno e do múltiplo. Para ele, a Complexidade é efetivamente o tecido de acontecimentos, ações, interações, retroações, determinações, acasos que constituem o nosso mundo fenomenal. Aliada aos princípios da Complexidade, outra área do conhecimento já bastante conhecida é a Teoria do Caos. Um sistema caótico tem um comportamento que apenas parece ser aleatório, mas na verdade acaba por ser determinístico (Lorenz, 1993).

Desse modo, a Complexidade articula diversas teorias cuja junção compõe um chamado sistema tronco (Leffa, 2006) e nos leva à denominação de paradigma, nesse caso, Paradigma da Complexidade. O que associa essas teorias, ou seja, o que há de comum entre elas, é o fato de que, em um sistema complexo, tudo está interligado e nada acontece por acaso (Leffa, 2006). Sendo assim, o Paradigma da Complexidade se tornou um termo guarda-chuva (Souza, 2011) ou um termo valise (Sobral, 2011), que recobre ou acolhe diversos campos de estudo.

Para entender a complexidade da relação entre PP e a emergência do CLIEAD adotamos características desses sistemas definindo-os como: dinâmicos, adaptativos, auto-organizativos e sensíveis às condições iniciais e a fatores externos. Sendo que a 
complexidade de sistemas educacionais como o CLIEAD independe da modalidade do curso, tomamos essas mesmas características para defini-lo como sistema adaptativo complexo.

Nesse sistema, em consonância com Lorenz (1993), Filatro (2007; 2008), Larsen-Freeman e Cameron (2008), Fleischer (2009), Braga (2009), Paiva (2009), e Bicudo (2011), dentre outros, percebemos que inúmeros fenômenos emergiram interrelacionados caracterizando fatores contextuais e complexos que restringiram ou favoreceram em diferentes graus os processos de ensino e aprendizagem e adaptativos do CLIEAD. Desse modo, retomando a proposta desses autores, passamos a tratar de fenômenos tais como: atratores, auto-organização, adaptabilidade e sensibilidade à condições iniciais e a fatores externos que incidiram no curso, assim como, incidem em todo e qualquer sistema caótico/complexo.

Assim, para apresentar o Projeto Pedagógico-PP do CLIEAD como documento contextualizado que compõe as condições iniciais para sua emergência no Ambiente Virtual de Aprendizagem - AVA, além desses aspectos introdutórios em que delimitamos nosso estudo, apresentamos algumas variáveis que emergiram em diferentes interações no contexto desse sistema no universo da Educação on-line, cenário dessa pesquisa, além de compartilhar e tecer alguns conceitos provenientes da teoria do Caos/Complexidade.

\section{PROJETO PEDAGÓGICO COMO CONDIÇÕES INICIAIS DE UM CURSO A DISTÂNCIA}

Nesse estudo, buscamos conhecer no PP do CLIEAD as condições iniciais de algumas variáveis que emergiram em diferentes interações no contexto desse sistema que atraiu grande número das experiências dos alunos para o contexto da formação on-line. Já que, reiterando Fleischer (2009), conhecendo bem as condições iniciais de um sistema, pode-se determinar com bastante precisão o conjunto de atratores de um sistema complexo, além de poder prever o comportamento das interações tomadas como um todo ao longo de um período de tempo.

Uma vez que atratores são "os estados que, estatisticamente, o sistema tende a assumir" (Fleischer, 2009, p. 77) e, considerando que a análise dessa tendência do sistema não constitui como enfoque desse trabalho, esclarecemos que nos apropriamos do conceito de atratores apenas para demonstrar o teor da relação entre PP e curso. Nesse contexto, consideramos o PP como condições iniciais para a emergência do CLIEAD enquanto sistema adaptativo complexo cuja materialização se dá pelo Design instrucional de seu AVA.

Nessa perspectiva, os acessos ao curso revelaram que o seu AVA parece operar como uma bacia atratora atraindo um grande número de experiências de formação 
inicial de professores de língua inglesa, buscando por estabilidade. Retomando Paiva (2009), quando um sistema se move para uma bacia atratora ele até atinge um momento de estabilidade.

Pela proposta de Lorenz (1993), entendemos que o estado presente de um sistema determina completamente ou quase completamente o estado futuro, mas não parece dizer isso. No caso do PP do curso, o seu estado presente até pode apontar para certa determinação de estado futuro pelo teor do documento que é um projeto e, até parece dizer isso pelo fato de estar supostamente acabado. Entretanto, em consonância com Bicudo (2011), percebemos o PP do curso como uma estrutura prévia que comporta planos de intenção, mas também guarda em si energia para tornar-se atual (realizado) pelo modo de realização do antevisto.

A ação de tornar atual o planejado destaca o que se efetivou de cada projeção, como o destino do ser do projetado, do como essas ações que vêm remetidas são acolhidas, compreendidas e tornadas efetivas. É nesse contexto que o PP se constitui como condições iniciais para emergência do CLIEAD. Organizado por uma associação de diversos elementos intimamente relacionados (equipe pedagógica, documentos oficiais, instituto etc.), o PP apresenta perfil caótico/complexo.

Portanto, o PP aponta diversos níveis de aleatoriedade não para si, mas para outro sistema ao qual está acoplado, que é o CLIEAD, demonstrando que os fenômenos caóticos são determinísticos, ou seja, para uma entrada totalmente conhecida e determinada (PP) surge uma resposta aparentemente aleatória. Para nós, o PP surge como estados iniciais de cada uma das variáveis que emergiu no sistema CLIEAD que compuseram seu conjunto de atratores.

\section{ATRATORES: ESTADOS E PADRÕES NA RELAÇÃO PROJETO PEDAGÓGICO E O CURSO DE FORMAÇÃO DE PROFESSORES A DISTÂNCIA}

Constituinte do CLIEAD, um grande sistema complexo, o PP se mostra como um pequeno, mas fundamental evento, que encadeado (encaixado) a outros, é capaz de determinar ou modificar radicalmente o regime de atuação e posturas de todos os envolvidos no processo de ensino e aprendizagem do CLIEAD. Isso implica que a menor alteração no PP poderia provocar grandes mudanças no curso levando a melhorar ou piorar, entre outras dimensões, a qualidade da aprendizagem dos alunos.

Podemos cogitar que um pequeno equívoco de compreensão das orientações propostas pelo PP poderia provocar, reduzir ou até interromper a evasão do curso dentre outras ações possíveis, ou seja, mínimas variações no comportamento dos 
interagentes podem dar rumos completamente diferentes a uma interação no sistema. Reiterando a proposta de Lorenz (1993), entendemos que tanto o PP quanto o CLIEAD apresentam grande sensibilidade à condições iniciais e a fatores externos.

Ao apontar ações futuras, o PP vai determinar um conjunto atratores não apenas possíveis, mas de fato observáveis, constituindo o conjunto de atratores do sistema CLIEAD. Retomando Fleischer (2009), esse autor define o atrator como estados que ocorrem com grande frequência, enquanto outros estados, embora plenamente possíveis, simplesmente não ocorrem. Em qualquer sistema, os estados que ocorrem repetidamente ou que são aproximados com frequência e de forma cada vez mais próximas constitui um conjunto de atratores.

Sendo assim, ao descrever o tutor como elemento de apoio do processo de estudos a distância: "o apoio e o acompanhamento ao estudante dar-se-ão de forma direta e mais constante pela ação dos tutores" (ILEEL/UFU, 2010, p. 22), o PP levou a figura do tutor a também operar como uma bacia atratora de um grande número de acessos. Os alunos repetidas vezes acessaram o ambiente na busca por orientação, apoio e acompanhamento do tutor, garantido pelo PP.

De acordo com a proposta de Larsen-Freeman e Cameron (2008) sobre identificação de atratores, três tipos de atratores foram identificados, quais sejam: fixo - sistema move para um estado estável; cíclico ou periódico - o sistema move periodicamente entre diferentes atratores; estranho - o sistema apresenta comportamento instável, (...) sendo que as menores perturbações podem fazer com que o sistema se mova de um estado para outro.

Nesse sentido, o PP aponta para certa determinação de estado futuro que vai emergir no AVA do CLIEAD. Dessa forma, não se pode prever com precisão a trajetória de todas as ações registradas no PP, mas sabe-se que todas passarão dentro de um determinado ambiente do CLIEAD (AVA ou encontros presenciais) e que nenhuma dessas ações acontecerá fora desse espaço e contexto, como mostrado pelo excerto do PP:

O Ambiente Virtual de Aprendizagem será organizado, na plataforma MOODLE, especificamente para este curso. Toda a comunicação e divulgação contarão com o auxílio da Internet e do telefone [...]

No desenvolvimento do curso, serão realizados nos polos, no mínimo, 1 (um) encontro presencial por semestre (ILEEL/UFU, 2010, p. 22-23, grifo original).

O AVA do curso materializado no Design Instrucional e os encontros presenciais podem ser apontados como um atrator fixo, na perspectiva de Larsen-Freeman e Cameron (2008), demonstrando que o sistema partindo do planejamento (PP) se moveu para o ambiente virtual em maior escala e em menor escala para os encontros 
presenciais. Essa determinação permaneceu estável, já que vigora até o final do curso.

Nesse caso, o sistema se moveu rumo a estabilidade ao propiciar atratores fixos como o ambiente virtual e os encontros presenciais que receberam ou atraíram os alunos e seus acessos durante todo o período de vigência do curso, demonstrando que todas as ações do curso ocorreram nesse contexto, sem alterar sua ordem.

Sendo assim, podemos apontar no PP variáveis, tais como: equipe multidisciplinar atuante, corpo discente com pré-requisitos suficientes (professores em exercício há três anos), recursos pedagógicos disponíveis no Design do curso, material instrucional disponível no AVA e impresso entregue aos alunos, que, entre outras, se constituem como um conjunto de atratores do CLIEAD. Entendemos que todas essas variáveis tiveram no PP suas condições iniciais que apontam diferentes estados fases no AVA.

No excerto seguinte, ao declarar que o tutor apoiará e acompanhará o aluno de forma direta garantindo interlocução no processo educativo do CLIEAD em ambiente on-line, o PP mostra o atrator ou estado que o curso enquanto sistema tende a seguir:

Por meio da tutoria, é possível garantir o processo de interlocução necessário ao projeto educativo [...] Para garantir um processo de interlocução permanente e dinâmico, a tutoria utilizará não só a rede comunicacional viabilizada pela internet, mas também outros meios de comunicação como o telefone, o telefax e os correios, que permitirão a todos os alunos, independente de suas condições de acesso ao polo de apoio presencial, contar com suporte e informações relativas ao curso (ILEEL/ UFU, 2010, p. 22, grifo nosso).

Para Larsen-Freeman e Cameron (2008), um espaço fase representa o 'cenário de possibilidades' de um sistema que através do cenário, ele muda e se adapta ao longo do tempo. A garantia do processo de interlocução necessário ao projeto educativo mediado pelo tutor, sobretudo, viabilizado pela internet apresentou diferentes espaços fase da aprendizagem no curso:

- Período de ambientação (acessos iniciais), cujo atrator foi a busca por conhecer o AVA e a formação do grupo de aprendizagem;

- Período de adaptação (acessos a informações), cujo atrator foram os fóruns de dúvidas, os fóruns gerais e os fóruns livres (café virtual) e a busca por orientação do tutor; 
- Período de acompanhamento do curso (acessos à instrução), em que o atrator foram os textos (guias didáticos e complementares), os vídeos, as atividades e os espaços de postagem dessas atividades;

- Período de tentativas de aprendizagem (acessos à mais informações) quando o atrator volta a ser a busca por orientações e acompanhamento, pois surge mais e novas dúvidas;

- Encontros presenciais (acessos ao polo presencial), cujo atrator foram as avaliações e seminários e, assim por diante.

Esse penúltimo espaço fase (d) mostrou que o sistema pendeu entre diferentes atratores como um pêndulo buscando por adaptação, podendo ser apontado como um atrator cíclico ou periódico, conforme caracterizado por Larsen-Freeman e Cameron (2008). O acesso à instrução provocou instabilidade do sistema de aprendizagem dos alunos, pois, as orientações (instrução) ao não serem compreendidas por eles causou um estado de desordem e confusão. Nesse aspecto, a desordem foi causada pela ênfase dada à fluência digital e no domínio do Inglês pelo sistema, além de consequentes dificuldades de acesso e de execução das atividades em ambiente $\mathrm{On}$ line, em substituição ao contexto de acessos livres a rede de internet e domínio da língua materna com que os alunos estavam acostumados.

Os comentários seguintes, retirados do fórum livre Café Virtual da disciplina Leitura Instrumental de Língua Inglesa-LILI, relatam sobre a falta de clareza da instrução, o pouco domínio digital e o pouco domínio do Inglês enquanto língua, condições que provocaram a instabilidade do sistema.

Falta de clareza da instrução-Aluna 1: Olá colegas, Não consegui entender o que de ser feito na atividade 4 -módulo 1 - introdução à morfologia do Inglês. "Depois de ter feito as atividades do livro, é importante que avaliemos seu aprendizado". Alguém entendeu? Preciso de ajuda.

Aluna 2: As atividades do guia não serão entregues, estou certa?

Aluno 3: Olá Tutora Estou com dificuldade de entender o exercício 3. Tenho de substituir a palavra que eu considere incorreta no texto? Ou somente dar o significado?

Pouco domínio digital - Aluna 4: Oi estou com dificuldade para entrar no AVA para responder aqueles exercícios.

Aluna 5: Em relação ao vídeo aula, modulo 1 da Língua Inglesa, como posso assistir? Desculpe sou ainda novata na net, tenho dificuldades... 
Pouco domínio do Inglês enquanto língua-Aluno 6: Como devo proceder em relação ao entendimento das palavras nos exercícios? Tradutor online ou dicionário? Pois tenho pouco entendimento da língua inglesa, mas muito interesse e vontade de aprender.

Aluno 7: Talvez o curso está sendo ministrado para professores de inglês que ainda não têm o diploma, eu que não sou professor e vim de um inglês publico passado na escola estou pensando em parar com o curso, pq não estou dando conta, peço ajuda...

Aluno 8: Por enquanto, não aprendi nenhuma língua além do português (grifo nosso).

Esses relatos, além de mostrarem um público alvo adverso ao proposto pelo PP, também mostram que no período de acompanhamento do curso (acesso à instrução) a busca por cumprir as tarefas propostas no tempo determinado provocou nova movimentação no sistema que se moveu novamente para o espaço fase anterior gerando novo processo de adaptação (acessos à informação) para manter a estabilidade. Larsen-Freeman e Cameron (2008) explicam que um sistema, no limite do caos, muda adaptativamente para manter a estabilidade. Por outro lado, grande diversidade de atratores estranhos pode mudar a rota de sistemas de formação de professores como é o CLIEAD gerando reciprocidade.

Entendemos que o sistema CLIEAD, de certa forma, segue uma rota previsível, mas o descrito por esses alunos demonstrou que eles sofreram restrições de atratores diferentes levando-os a exibirem dinâmicas e comportamentos que também causaram perturbação no sistema. Muitos deles foram atraídos para um atrator estranho dentro do sistema educacional, sendo que alguns desses alunos (3, 4 e 7) moveram para a bacia atratora da aprendizagem de línguas, já que não tinham fluência em Inglês buscaram novas formas de aprendê-lo.

Outros (6 e 8) não mudaram nem se adaptaram e abandonaram o curso, escolhendo o caminho mais cômodo. Os demais $(1,2,4$ e 5) foram atraídos para a bacia atratora da aprendizagem coletiva, buscando auxílio para as dificuldades (na língua e de acesso ao AVA) no próprio grupo e no tutor. O espaço fase que envolveu o período de tentativas de aprendizagem, no entanto, englobou diversos atratores estranhos, tantos que levou o sistema a apresentar um comportamento bastante turbulento e instável. A perturbação da busca por informações o fez pender recursivamente movendo para outro estado ou nova fase de adaptação em que todos os seus agentes pendiam para colaboração na busca pela estabilidade.

Essa movimentação ainda pode ter sido impulsionada pelo fato de que, embora o PP tivesse garantido o acompanhamento ao estudante pelo tutor, ao iniciar o curso houve a necessidade desse acompanhamento ser feito por coordenadores de curso e até por coordenadores de tutoria. Isso pelo fato de que até então, os tutores que 
efetivamente acompanhariam os alunos não tiveram suas situações profissionais regularizadas.

Essa alteração momentânea nos planos, em que o curso começou sem ter toda a equipe atuando, fez com que o sistema oscilasse pendendo para a continuidade do processo e seguisse outra rota ao adaptar-se ao contexto atual. Na falta de um elemento fundamental, o sistema se auto-organizou, trocou insumos com o ambiente e com outros elementos, adaptando-se para manter-se vivo encontrando meios para a estabilidade na colaboração e na reciprocidade entre os interagentes.

No caso, a falta de um dos elementos da equipe multidisciplinar-proposta pelo PP-emerge no Design do CLIEAD como um atrator periódico em que o sistema move entre diferentes estados, causando desequilíbrio, parecendo haver certa tendência de aumento na busca por soluções de problemas e dúvidas dos interagentes em períodos de maior ou de menor intensidade. Assim, ao longo do período sem tutor até chegar ao ponto em que os tutores assumem suas funções e, ainda, certo tempo depois, observamos um aumento gradual de participação dos alunos nos fóruns de interação geral, ao passo que, após a chegada dos tutores, pudemos observar uma redução expressiva e gradativa dessas participações. Braga (2009) explica que as constantes ações e reações dos agentes fazem com que o sistema se torne dinâmico e suscetível às mudanças que resultam de feedback (produto, efeito ou insumo transformado em energia), adapte-se ao novo ambiente e aprenda por meio da experiência.

Observamos que essa movimentação se mostrou não apenas porque houve migração dos acessos em ambientes dos fóruns gerais para os específicos, mas também, por causa da redistribuição de funções. Ao assumirem suas funções, os tutores além de cumprir papel de mediador da aprendizagem nos conteúdos das disciplinas de cada módulo, eles esclareceram dúvidas e reforçaram a aprendizagem dos alunos.

Essa ação apresentou ligeira tendência em resolver problemas e dúvidas dos alunos em relação ao AVA e ao conteúdo, além de redirecioná-los, desafogando os fóruns como um todo, levando o sistema à organização momentânea. Essa organização, no entanto, surgiu, espontaneamente, a partir da desordem e não pareceu ser dirigida por leis físicas conhecidas. De alguma forma, a ordem surge das múltiplas interações entre as unidades componentes.

Sendo assim, o contexto surge como um elemento fundamental influenciando diretamente essas relações. Compreendendo o contexto como uma interrelação de circunstâncias que acompanham um fato ou situação (Filatro, 2007), reconhecese, portanto, a necessidade de adaptar qualquer proposta instrucional de ensino a distância ao seu contexto de aplicação. Ao pensar a necessidade de se criar ambientes 
propícios à emergência de aprendizagem, percebe-se que é pela interação entre as pessoas que a contextualização dessas relações se efetiva.

\section{QUANTO A ALEATORIEDADE DO SISTEMA}

Nesse contexto de múltiplas interações, a aleatoriedade se mostra ao observarmos a distribuição de mensagens nos fóruns de modo individualizado e a ausência/ presença do tutor no sistema. No entanto, vendo esse comportamento na totalidade, as tendências conferem ao sistema um alto grau de previsibilidade. Isso quer dizer que ao passar do tempo, o número de participação dos alunos na busca por soluções de problemas e de dúvidas pode chegar a zero nos fóruns do CLIEAD, sobretudo, nos fóruns livres como o Café Virtual.

O próximo excerto advindo do Fórum de Notícias do Ambiente Geral de Interação do CLIEAD demonstra a oscilação do sistema, se auto-organizando para manter-se atuante:

Coordenadora do curso: Bem vindos à semana de familiarização do nosso ambiente virtual de aprendizagem, o MOODLE!!!

É com muito prazer que os recebemos aqui para praticarmos, antes das primeiras disciplinas, alguns recursos e ferramentas disponíveis para nossos processos de aprendizagem/construção/circulação de saberes (05/09/2011).

Coordenadora do curso: Para inserir um comentário, basta clicar, ao fim da mensagem de apresentação do fórum, em "Acrescentar novo tópico de discussão". Vocês estão visualizando esse botão? Ele está disponível para vocês (5 de setembro).

Coordenadora de Tutoria: Sejam bem vindos ao curso! Sou a coordenadora de tutores da área de inglês. Em virtude de procedimentos administrativos para efetivação da contratação de seus tutores, gostaria de informar que em breve vocês terão acompanhamento para cumprimento de suas atividades. Por enquanto, pedimos um pouco de paciência e que postem suas dúvidas nos fóruns de cada disciplina, as quais serão atendidas pelos professores e coordenadores dentro de suas possibilidades (15/09/2011).

Esse estado em que houve a necessidade de as interações do curso serem abertas e acompanhadas até certo tempo pela própria coordenadora do curso durou pouco tempo, pois a partir de 15 dias depois do início do curso, os tutores começaram a participar das interações e assumiram a mediação do processo de ensino e aprendizagem. Os dados mostraram que durante o tempo em que a ação dos tutores não tinha sido regularizada, a coordenadora e professores das disciplinas acompanharam diretamente os alunos, dando-lhes o suporte e acolhidas necessários todo o tempo, suprindo a falta do tutor, permitindo que o processo transcorresse 
no sistema. Isso porque esse tipo de sistema tem a capacidade de adaptar-se e essa capacidade o leva à auto-organização e à emergência de novos padrões e comportamentos (Braga, 2009).

Naquele momento, o professor da disciplina surgiu como o elemento que mais exerceu o papel de tutor, acompanhando diretamente o aluno até que os tutores começassem o trabalho, forçando à adaptação do sistema, o que pode ser percebido no seguinte excerto colhido do Fórum de Notícias e Café Virtual respectivamente:

Coordenadora do curso: Fico feliz que tenham iniciado suas atividades nas disciplinas, e agradeço a compreensão com relação aos problemas técnicos no Moodle neste começo. Solicito a todos que, a partir de agora, façam suas perguntas (sobre conteúdo, agenda ou de ordem técnica) a respeito das disciplinas em andamento nos fóruns de dúvida das próprias disciplinas..., okay? (13/09/2011).

Professor da disciplina: Caros, enquanto os tutores estão chegando, quem estiver com dúvida, entre em contato comigo através desse fórum de dúvidas. Como os guias impressos ainda não chegaram, por favor, façam o download do primeiro módulo em pdf (disponível logo no começo das atividades programadas)(12/09/2011).

Professora da disciplina: Você já está no AVA, que quer dizer ambiente virtual de aprendizagem, configurado a partir da plataforma Moodle. Abaixo do café virtual já se encontram todos os links para as atividades da primeira quinzena. Em primeiro lugar, clique no guia de estudos e faça a leitura para se inteirar melhor do que deve ser feito (13/09/2011).

Pode-se perceber que a coordenadora agradece aos alunos e os direcionam para que recebam o acompanhamento dos demais profissionais que o acompanharão na trajetória do curso. Esse dado ainda mostra que, além da coordenadora do curso e da coordenadora de tutoria, o professor exerceu dupla função: professor regente ${ }^{1}-$ responsável, de acordo com o PP, pelas disciplinas de cada módulo do curso, estando à disposição para esclarecimento de dúvidas de alunos e tutores, a partir de cronograma a ser estabelecido junto a cada docente e, de tutora-papel de mediador da aprendizagem nos conteúdos das disciplinas de cada módulo, esclarecendo dúvidas e reforçando a aprendizagem dos alunos [...] conduzindo atividades interativas e, principalmente, de motivação (ILEEL/UFU, 2010).

Tendo em vista os aspectos intrínsecos da sala de aula on-line tais como interrelações de elementos indissoluvelmente associados organizados para a composição de um ambiente que favorecesse à aprendizagem, compreendemos esse ambiente do curso como um sistema complexo que comportou diversos outros subsistemas que emergiram a partir das relações entre agentes nas salas de aula online do CLIEAD, promovendo a chamada aprendizagem eletrônica (Filatro, 2008), propiciando colaboração entre seus diversos elementos em prol da aprendizagem. 
Um ambiente que seja propício à aprendizagem emerge a partir da articulação de diversas condições e a acomodação de vários fatores contextuais em estreita relação com o seu meio de aplicação. Assim, inúmeras condições foram necessárias para emergência de um ambiente propício à aprendizagem na sala de aula on-line do curso a partir das condições iniciais propostas por seu projeto pedagógico entre elas a colaboração e reciprocidade entre agentes. Graças à capacidade de adaptação do sistema, este foi impulsionado à auto-organização e à emergência de novos padrões e comportamentos.

\section{COMPORTAMENTO INSTÁVEL DO SISTEMA: MÚLTIPLAS FUNÇÕES DOS INTERAGENTES}

Entendemos que a chegada dos tutores apontou certa tendência de redirecionamento das funções no curso, pois ao assumir o seu papel, o tutor desafogou os demais membros da equipe, permitindo que cada um deles voltasse a assumir sua real função no CLIEAD. Isso quer dizer que ao longo de um período, o número de participação do coordenador, coordenador de tutoria, professores nos fóruns gerais e específicos, deve reduzir a um número mínimo.

Nesse caso, a implementação do curso envolveu elementos e agentes que interagiram entre si, em constante adaptação com o ambiente, à medida que buscou acomodação mútua para otimizar possíveis benefícios que assegurassem sua sobrevivência (Braga, 2009). Em qualquer sistema, os estados, que ocorrem repetidamente ou que são aproximados com frequência e de forma cada vez mais próxima, constituem seu conjunto de atratores.

Os dados mostraram, por um lado, dois estados estranhos que embora possíveis de acontecer não estavam previstos ou determinados no PP, que seria a dupla ou tripla função de profissionais ligados à gestão e docência do curso e a movimentação causada nos alunos por conta da ausência do tutor. Esses atratores compuseram os espaços fase período de ambientação (acessos iniciais) e perdurou até o período de adaptação (acessos a informações), atraindo os alunos para os fóruns de dúvidas, os fóruns gerais, especialmente, os fóruns livres (café virtual) em busca por orientações diversas.

Embora a sobrecarga dos elementos do sistema não estivesse prevista no PP, a necessidade do sistema de manter-se vivo pendeu para o lado da múltipla função dos elementos, atraindo-os para um determinado ponto em que deveriam se unir para suprir a falta de outro elemento-chave do processo que seria o tutor. Como em um sistema caótico/complexo o estado é determinado pelas condições iniciais (Fleischer, 2009), a movimentação entre os pontos aponta a tendência ou direção que o sistema vai seguir, sendo passível de previsão. 
Uma vez que as condições iniciais (PP) apresentaram o tutor como um elementochave do sistema, mas esse elemento não se concretizou no curso, a problemática causada pela não atuação desse elemento no sistema poderia ser determinada com bastante previsão. Retomando Fleischer (2009), entendemos que pode-se determinar com bastante precisão um conjunto de atratores de um sistema, uma vez que as condições iniciais do estado sejam bem conhecidas.

Nesse contexto, o exercício de múltiplas funções por parte desses profissionais e a desorientação dos alunos frente a tantas dúvidas se constituem como um atrator estranho levando o CLIEAD a apresentar um comportamento instável, induzindo o sistema se mover de um estado para outro com certa frequência. Entretanto, a múltipla função dos agentes envolvidos no processo ensino e aprendizagem do curso é um estado que pertence ao conjunto de atratores de qualquer sistema educacional. Embora não planejada, essa ação acontece com frequência provocando inúmeros movimentos e desequilíbrios no sistema.

Muitos dos recursos apontados no PP não foram viabilizados ao aluno no Design instrucional do CLIEAD e a não disponibilização desses recursos se constituiu como fontes desestabilizadoras do sistema. Ressaltamos que alguns recursos como fóruns, chats, videoaulas foram inviabilizados pela ausência do tutor que assume como tarefas exclusivamente suas a disponibilização e abertura desses recursos, ou seja, somente o tutor pode abrir chats e fóruns. A oferta de recursos pedagógicos colaborativos mediados pelo tutor viria provocar certa acomodação do sistema, mas a demora da entrada do tutor como elemento articulador do processo de ensino e aprendizagem do curso abalou toda sua estrutura.

Podemos afirmar que cada unidade de aprendizagem ou módulo apresentado no Design comportava e articulava de modo contextualizado (relacionado ao PP) cada elemento apontado no PP, tais como: objetivos de aprendizagem, papeis dos agentes, atividades de aprendizagem, duração e os períodos, conteúdos e objetos de aprendizagem, as ferramentas digitais, as avaliações etc. Ao observarmos os módulos, pudemos verificar que não se tratavam de peças sequenciais independentes dos demais componentes, mas uma rede dinamicamente associada, cujas partes se conectam umas com as outras de modo indissociável.

O PP se mostrou como uma matriz norteadora para o Design, com o propósito fundamental de atender à demanda oriunda da adesão do Instituto de Letras e Linguística da instituição às políticas de formação de professores para atuarem na rede de Educação Básica, a fim de habilitar, à distância, profissionais (professores de Inglês) já em exercício no magistério. Nesse caso, o PP, entrada conhecida para o sistema adaptativo complexo CLIEAD, foi organizado no sentido de compor um ambiente On-line que fosse propício à aprendizagem desse aluno, o qual pudesse ter desenvolvidas suas competências e habilidades. 
Isso implicou em uma mudança de posturas que envolveram a incorporação de tecnologias digitais às práticas pedagógicas historicamente construídas em termos de estrutura de ensino presencial convencional do instituto, demonstrando que em sistemas caótico/complexos, como o curso, entradas perfeitamente conhecidas como o PP podem gerar respostas aleatórias como as transformações provocadas pela mudança do contexto presencial para o a distância.

Nesse sentido, o PP orientou toda a dinâmica curricular, apresentando na perspectiva da Educação a Distância-EAD as diretrizes que deveriam ser consideradas na proposta metodológica, estratégias de ensino e de aprendizagem, os recursos educacionais etc. Nesse caso, o uso do AVA, planejado pelo PP, visou propiciar aos alunos a oportunidade de lidar com a formação a distância, vivenciando as possibilidades e os desafios das tecnologias digitais utilizadas de modo pedagógico em um ambiente que fosse favorável à aprendizagem. Nesses termos, projetado para um contexto particular, o PP se mostrou bastante sensível às condições locais e procurou adaptar-se às circunstâncias de situações específicas que seria a atuação em contexto On-line, até então, pouco praticado pela instituição que o acolheu.

\section{CONSIDERAÇÕES FINAIS}

O projeto pedagógico influenciou as relações no Design instrucional à medida que amparou a organização do ambiente no que se refere a aspectos pedagógicos, legais e de instrução. Como uma estrutura prévia, ele comportou inúmeros planos de intenção que organizaram, fundamentaram sem, no entanto, determinar ou interferir diretamente nas ações e relações que ocorreram no Design.

Isso significa que todas as ações propostas no PP, de alguma forma, apareceram no Design do curso, sem, contudo, inibir a autonomia de professores no que se refere à pratica pedagógica, dos tutores em seu processo de mediação, dos alunos na busca por formação nem dos demais agentes da equipe técnica na busca por propiciar acessibilidade e interatividade aos participantes do curso. Essa forma de influência apresenta o Design do CLIEAD sendo diretamente influenciado pelo PP, no sentido de ser o todo projetado na parte e a parte sendo reflexo do todo.

Considerando a relação entre PP e o Design instrucional do CLIEAD concluímos que, o que foi registrado no projeto foi aplicado e, de algum modo, essas ações apareceram no Design e puderam contar com múltiplos interlocutores, por exemplo, professores, alunos, políticas públicas, sociedade etc.. Ao organizar as ações no Design, o PP deixou mostrar as diversas concepções (concepção de docência, de aluno, de ensino, de aprendizagem, de EAD, etc.), crenças, culturas e o pretendido por todos os agentes. Pelo Design, conseguimos acompanhar as nuanças do projetado a partir de cada dimensão do curso, seja em aspectos pedagógicos, profissionais ou legais. O PP, de fato, se mostrou como um polo de intencionalidade. 
Destacamos que não dá para prever os limites do alcance das propostas do PP, mas a interdependência dos seus diferentes elementos e interagentes favoreceram à organização de ambientes que acomodaram, de certa forma, diversos fatores contextuais e propiciaram situações de aprendizagem aos alunos no CLIEAD que refletem o planejamento. Nessa perspectiva, o PP e Design aparecem interrelacionados por meio de uma operação não-linear que constitui os sistemas caóticos que se repetem com o resultado (output) de um cíclico, tornando-se entrada (input) do ciclo seguinte.

Sendo assim, da relação entre PP e Design, verificamos a emergência de um ambiente propício à aprendizagem no processo de adaptação do CLIEAD, enquanto sistema adaptativo complexo, entretanto, os apontamentos do PP não alcançaram o público desejado (Professores de Inglês, atuantes há pelo menos três anos), carecendo de uma reconfiguração para atender ao público ingressado em suas necessidades e anseios. Ao manter os mesmos objetivos instrucionais e configuração projetados pelo PP, entendemos que o CLIEAD não propiciou a aprendizagem almejada, uma vez que sua proposta de Design instrucional não foi adaptada ao contexto de aplicação.

Desse modo, iniciadas a partir do PP, a condições para a complexidade emergiram no Design sem envolver nenhum grau de predição ou prescrição, contudo apontaram os caminhos do processo de adaptação desse sistema, que se mostrou pouco sensível às condições locais e às circunstâncias das situações específicas do CLIEAD. Assim fatores como: público alvo adverso ao projetado pelo PP, desconhecimento da Língua Inglesa, falta de pré-requisitos para o curso, falta de fluência digital, falta de fluência em Inglês, demora da chegada dos tutores, inexperiência com cursos a distância tanto pela instituição quanto pelos cursistas, dentre outros fatores influenciaram negativamente no processo de adaptação do curso enquanto um sistema complexo. Tais fatores encontraram um Design inflexível do CLIEAD e se estabeleceram.

Com um Design padronizado, rígido e procedimentalizado, o CLIEAD não apresentou flexibilidade de currículo, de tempo ou lugar que pudesse oportunizar emergência de ambiente propício à aprendizagem contextualizada e espaço para escolhas e autonomia dos alunos, ocasionando expressiva evasão do curso. Orientada pelo $\mathrm{PP}$ e adaptada à modalidade de $\mathrm{EAD}$, a instrução do curso se mostrou fixa, as abordagens instrucionais previamente selecionadas, com conteúdo predeterminado, desconsiderando o contexto de aplicação ao tratar o grupo de participantes como um todo homogêneo.

A relação entre o PP e o Design instrucional do curso ainda demonstrou ser de caráter recursivo e dinâmico, uma vez que seus produtos e os seus efeitos foram, ao mesmo tempo, causas e produtores que os produziram, ou seja, o PP organizou ações que foram aplicadas ou se materializaram no Design e os reflexos dessas ações (dinâmicas, tarefas, atividades etc.) se mostraram enquanto projeções do PP e, assim, 
recursivamente. No entanto, o processo de contextualização do Design instrucional se deu a partir do PP, a nosso ver, revelado em uma proposta inicial de atividades pré-especificadas que foram dispostas em uma programação do AVA, de modo que cada disciplina era organizada como uma sala de aula no ambiente e trazia consigo as concepções que fundamentaram a prática pedagógica de cada professor.

\section{NOTAS}

1. Relevante acrescentar que os professores regentes ainda acumulam a função de professor autor em que são responsáveis pela confecção dos materiais didáticos/ conteúdos das disciplinas que serão ministradas no curso.

\section{REFERÊNCIAS BIBLIOGRÁFICAS}

Bicudo, M. A. V. (2011). Aspectos da pesquisa qualitativa efetuada em uma abordagem fenomenológica. In M. A. V. Bicudo, Pesquisa qualitativa segundo a visão fenomenológica. (pp. 29-40). São Paulo: Cortez.

Braga, J. C. F. (2009). A presença cognitiva em comunidades de aprendizagem On-line. In V. L. M. O. Paiva, e M. Nascimento, Sistemas adaptativos complexos: língua(gem) e aprendizagem. (pp.131-148). Belo Horizonte: Faculdade de Letras da UFMG.

Fleischer, E. (2009) Caos/complexidade na interação humana. In V. L. M. O. Paiva, e M. Nascimento, Sistemas adaptativos complexos: língua(gem) e aprendizagem. (pp. 73-92). Belo Horizonte: Faculdade de Letras da UFMG.

Filatro, A. (2007). Design instrucional contextualizado. 2. ed. São Paulo: Editora Senac. . (2008). Design instrucional na prática. São Paulo: Pearson Education do Brasil.

Larsen-Freeman, D; Cameron, L. (2008). Complex systems and Applied Linguistics. New York: Oxford.

Leffa, V. J. (2006). Transdisciplinaridade no Ensino de Línguas: a perspectiva das Teorias da Complexidade. Revista
Brasileira de Linguística Aplicada, 6(1), 27-49.

Lorenz, E. N. (1993).The Essence of Chaos. Seattle: University of Washington Press.

Morin, E. (2003). Introdução ao pensamento complexo. Lisboa: Piaget.

Paiva, V. L. M. (2009). Caos, complexidade e aquisição de segunda língua. In V. L. M. O. Paiva, e M. Nascimento, Sistemas adaptativos complexos: língua(gem) e aprendizagem, (pp. 187-204). Belo Horizonte: Faculdade de Letras da UFMG.

Sobral, A. (2011). Reflexões sobre as concepções de leitura de alunos de Mestrado. In A. M. F. Barcelos, (Org.), Linguística Aplicada: reflexões sobre ensino e aprendizagem de língua materna e língua estrangeira. (pp. 4766). Campinas: Pontes Editores. Coleção: Novas perspectivas em Linguística Aplicada, v. 13.

Souza, V. V. S. (2011). Dinamicidade $e$ adaptabilidade em comunidades virtuais de aprendizagem: uma textografia à luz do paradigma da complexidade. $256 \mathrm{f}$. Tese (Doutorado em Estudos Linguísticos)-Faculdade de Letras, Universidade Federal de Minas Gerais, Belo Horizonte, MG.

Universidade Federal de UberlândiaInstituto De Letras E Linguística. (2010). 
Projeto Pedagógico do Curso de Letras: Licenciatura em Inglês e literatura de Língua Inglesa-PARFOR. Modalidade a Distância. Comissão PARFOR. Uberlândia: UFU/ILEEL.

\section{PERFIL ACADÊMICO E PROFISSIONAL DOS AUTORES}

Eliamar Godoi. Professora Adjunta da Faculdade de Educação da Universidade Federal de Uberlândia - FACED/UFU. Doutorado em Estudos Linguísticos. Coordenadora do Curso de Aperfeiçoamento em Língua Brasileira de Sinais - Libras a distância-MEC/SECADI. Pesquisadora do Grupo de Pesquisas em Estudos da Linguagem, Libras, Educação Especial e a Distância e Tecnologias-GPELEDT. Atua nos seguintes temas: Processo de ensino e aprendizagem de Libras, Educação Especial, Educação a Distância e Linguagens.

E-mail: eliamarufu@gmail.com

Roberval Montes da Silva. Professor da Universidade Estadual de Goiás - UEG, Unu Itumbiara. Especialização em Finanças e Planejamento Empresarial pela Universidade Federal de Uberlândia. Professor formador do Curso de Aperfeiçoamento em Língua Brasileira de Sinais - Libras a distância-MEC/SECADI. Pesquisador do Grupo de Pesquisas em Estudos da Linguagem, Libras, Educação Especial e a Distância e Tecnologias-GPELEDT. Atua na área de Economia, com ênfase em Economia Geral e na área de Educação a Distância.

E-mail: robervalms@hotmail.com

\section{ENDEREÇO}

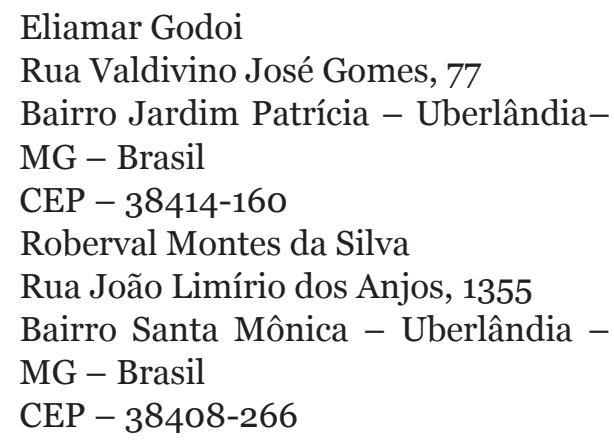

Fechas de recepción del artículo: 05/05/2014 Fecha de aceptación del artículo: 13/09/2014 


\section{Como citar este artículo:}

Godoi, E., e Montes da Silva, R. (2015). Emergência de ambiente propício à aprendizagem da relação entre projeto pedagógico e ambiente virtual em cursos a distância: uma abordagem complexa. RIED. Revista Iberoamericana de educación a Distancia, volumen 18, $\mathrm{n}^{0} 1$, pp. 171-189. 